\title{
A CONTRIBUTION TO THE POPULATION BIOLOGY OF OENOTHERA GRANDIFLORA L'HER.'
}

\author{
Erich Steiner ANd Wilfried Stubbe
}

\author{
Division of Biological Sciences and Matthaei Botanical Gardens, \\ University of Michigan, Ann Arbor, Michigan 48109 and Botanical Institute, \\ University of Duesseldorf, 4000 Duesseldorf, Germany
}

\begin{abstract}
A B S T R A C T
The cytogenetic characteristics of samples from 12 populations of Oe. grandiflora L'Her, were investigated. The combination of characters which distinguishes Oe. grandiflora from its sympatric relative, Oe. biennis, includes deeply scalloped margins of the rosette leaf bases, red flecks on the young leaves, clear green stem tips with erect or semi-erect hairs, and clusters of lateral branches at the tip of the central shoot or primary basal branches. In general, flowering is in response to short days and occurs from early August until late October. The species, originally believed to be indigenous to southern Alabama, is found throughout the Southeast, but its presettlement distribution remains uncertain. Populations of Oe. grandiflora consist largely of structural homozygotes or forms showing small circles of chromosomes at meiosis, although one plant with a circle of ten and two pairs was observed. Five different chromosomal end arrangements have been identified; none of these differ, however, by more than two interchanges. The arrangement considered ancestral for the subsection Euoenothera is found in nine of the populations. The species is composed of both self-incompatible as well as self-compatible forms. Incompatibility alleles have been found in 7 of the 12 populations analyzed.
\end{abstract}

OENOTHERA GRANDIFLORA L'Her. has received relatively little attention in the cytogenetic and evolutionary studies of Oenothera subsection Euoenothera even though a better understanding of this taxon may shed light on several questions regarding the evolution of the subsection. Oenothera grandiflora was originally discovered by William Bartram on the banks of the Tensaw River in southern Alabama in 1773 (see Harper in Bartram, 1958) and described in Aiton (1789). It has been viewed as a relic species, until recently believed to be largely restricted to the vicinity of Mobile, Alabama (Cleland, 1972), but now shown to be distributed throughout the southeastern states. Collections are known from North and South Carolina, Florida, Mississippi, and Tennessee as well as Alabama (Raven, P., Wagner, W., pers. commun.). However, the species is by no means common in comparison with Oe. biennis. The collections grown and analyzed cytogenetically by Cleland were only from the Mobile area and proved to be self-compatible structural homozygotes, all of which possessed the chromosomal end arrangement believed to be ancestral for the subsection Euoenothera (Cleland, 1972). Since that time, analysis of additional collections has revealed the presence of incompatibility alleles in certain grandiflora populations (Stubbe and Raven, 1979). Moreover, some diversity in chromosomal end

\footnotetext{
1 Received for publication 19 December 1983; revision accepted 18 April 1984.
}

arrangement has been found among these forms.

A more detailed study of Oenothera grandiflora is warranted for several reasons. A number of observations point to Oe. grandiflora as one of the progenitors of Oe. biennis (biennis Groups I \& II of Cleland), and it may be the sole progenitor of Oe. nutans (syn. austromontana or biennis Group III of Cleland). Were the latter relationship established with reasonable certainty, it would mean that a complex heterozygote can arise directly from within a single structurally homozygous species as well as through hybridization between previously isolated and differentiated populations. An understanding of the distribution and ecology of $O e$. grandiflora may explain its relic status and the competitive relationships with its Oe. biennis derivatives. Finally, the presence of both self-compatible (Sc) and self-incompatible (Si) forms in the same species offers an opportunity to study the evolution of self-compatibility from self-incompatibility.

MATERIALS AND METHODS-The collections utilized for the current study are listed in Table 1 . They were grown at the University of Duesseldorf, although a portion of the hybrids produced with these strains was subsequently analyzed at the Matthaei Botanical Gardens of the University of Michigan. Some strains were obtained through the efforts of Dr. Peter Raven; others came from the collection of R. E. Cleland. In most cases the number of plants from 
TABLE 1. Collections analyzed in the current study

\begin{tabular}{|c|c|c|c|c|}
\hline Collection & Source & Collector & Date & No. of specimens \\
\hline Avalon & $\begin{array}{l}\text { Avalon, FL; Avalon Beach Rd, } \\
\text { just north of junction of Rtes } \\
\text { C281A and C191A }\end{array}$ & R. K. Godfrey & 19 Oct 1978 & $\begin{array}{l}\text { seed from several } \\
\text { plants }\end{array}$ \\
\hline Bellamy & $\begin{array}{l}\text { Bellamy, AL; Sumter Co. U.S. } \\
\text { Hwy } 80\end{array}$ & $\begin{array}{l}\text { Sam B. Jones \& Jud } \\
\text { K. Arrington }\end{array}$ & 16 Aug 1974 & not specified \\
\hline Brewton & $\begin{array}{l}\text { Brewton, AL; flood plain, Cone- } \\
\text { cuh } R \text {. on Co Rd } 4,12 \mathrm{mi} \\
\text { east of Brewton }\end{array}$ & Erich Steiner & 26 Sep 1981 & $\begin{array}{l}\text { seed from each of } \\
52 \text { plants }\end{array}$ \\
\hline Martin Branch & $\begin{array}{l}1.2 \mathrm{mi} \text { south of Seabury Creek } \\
\text { (see below) }\end{array}$ & P. Biebel & 13 Oct 1962 & unspecified \\
\hline Monteagle & $\begin{array}{l}\text { Along I24 southeast of Montea- } \\
\text { gle, TN }\end{array}$ & R. Kral & Sep 1979 & seed from 2 plants \\
\hline Santa Rosa & $\begin{array}{l}\text { Along RR by Hwy } 900.5 \mathrm{mi} \\
\text { east of junction with St Hwy } \\
87 \text {, Santa Rosa Co, FL }\end{array}$ & R. K. Godfrey & 19 Oct 1978 & $\begin{array}{l}\text { seed from several } \\
\text { plants }\end{array}$ \\
\hline Seabury Creek I ${ }^{b}$ & $\begin{array}{l}1.4 \text { mi south of junction Co Rd } \\
7 \text { \& St Hwy } 59, \text { south of } \\
\text { Stockton, AL }\end{array}$ & P. Biebel & Oct 1962 & unspecified \\
\hline Seabury Creek II $^{\mathrm{b}}$ & $\begin{array}{l}1.4 \text { mi south of junction Co Rd } \\
7 \text { \& St Hwy } 59 \text {, south of } \\
\text { Stockton, AL }\end{array}$ & P. Biebel & Oct 1962 & unspecified \\
\hline Stockton $I^{b}$ & Stockton Store, Stockton, AL & P. Biebel & Oct 1962 & $\begin{array}{l}4 \text { plants, } 1 \text { plant, } \\
\text { several plants }\end{array}$ \\
\hline Stockton $\mathrm{II}^{\mathrm{b}}$ & Stockton Store, Stockton, AL & P. Biebel & Oct 1962 & several plants \\
\hline Tuscaloosa & Mobile delta & J. S. Lloyd & Aug 1944 & unspecified \\
\hline York & $\begin{array}{l}\text { 1.7 mi south of York, Sumter } \\
\mathrm{Co}, \mathrm{AL}\end{array}$ & Sam B. Jones & unknown & unspecified \\
\hline
\end{tabular}

a Population located by R. Kral.

b The Seabury Creek and Stockton strains were obtained from Dr. R. E. Cleland under the designations I and II, the basis of which is not known; presumably they were derived from different plants of the original collection.

which seed was taken remained unspecified and probably was no more than one to several individuals. In those collections in which seed was known to come from individual plants, separate strains were maintained and designated by different numbers, if collected at the same site. The population sample from Brewton, Alabama, collected by one of the authors in 1981, represented an effort to determine the composition of a single population in greater depth. The original intent was to obtain a number of such mass collections, but attempts to locate several separate stands of Oe. grandiflora on two field excursions of limited duration proved fruitless. In the late summer of 1983 another attempt was made to locate $O e$. grandiflora populations in southern Alabama, this time with more success. The results from analysis of these newer collections will be reported later.

In the case of the Brewton collection, seeds were taken from each of 52 plants scattered throughout the population. The seeds of each plant were germinated and grown as a separate culture. Seeds of Oenothera are generally germinated in January or February and the seedlings grown to the rosette stage in the greenhouse, before being transplanted to the experimental garden when the danger of frost is over. Oe. grandiflora usually behaves as a short-day species and does not bloom in the North until very late in the season. In order to analyze an appreciable number of plants cytogenetically, short-day treatment to induce early flowering is essential. The treatment must be applied after the plants have broken the rosette stage. Plants exposed to short days were held in the greenhouse during the day; a similar series was kept in the greenhouse without treatment as a control. The remaining plants of a culture, generally 12 to 15 , were planted in the experimental garden.

The morphological characters were recorded from the field grown plants only.

Chromosome configurations at meiosis were determined by the aceto-carmine method. Se- 
pals and petals of buds believed to be in the proper stage were removed and the remainder of the bud fixed in 3:1 alcohol-acetic acid. After fixation the buds were boiled in aceto-carmine for $5 \mathrm{~min}$ and the anthers squashed on a slide. One to several plants of a strain were usually determined. Many of the strains have been maintained for a number of years and the configurations determined in successive generations. In the Brewton series an effort was made to determine the meiotic configuration of at least one plant from each culture and of a larger number of plants within each of several cultures.

Plants from 14 of the Brewton cultures were crossed with tester strains of known segmental arrangement in order to determine the segmental arrangements occuring in the population; the method of analysis is described in Cleland (1972).

Two methods were used to test for self-compatibility. Mature buds in which pollen had begun to shed, were opened, hand pollinated, bagged, and fruit set recorded. In addition, mature buds were collected in vials filled with water, opened, and self pollinated, after which they were incubated at $28 \mathrm{C}$ for $24 \mathrm{hr}$. The styles were then removed from the flowers, treated with a $10 \%$ IKI solution and squashed between two microscope slides. Self-compatibility or incompatibility was established by the presence or absence of pollen tubes at the base of the style. Pollen tubes are readily recognizable because of the deeply staining, spindle-shaped starch grains which they contain.

In order to test for the presence of Si alleles which might be sequestered in heterozygotes ( $\mathrm{ScSi}$ ) and thus not detectable by selfing, plants from each of 21 Brewton cultures were crossed as pollen parents with an artificial hybrid, albicans $\cdot$ undans, from the cross, Oe. suaveolens Grado $\times O e$. bauri to give albicans. Brewton combinations. The albicans complex is inactive in the pollen; thus if the Brewton complex carries an Si allele, the hybrid will be self-incompatible. Six plants of each of the 21 different hybrid cultures were tested for selfincompatibility.

The geographic range of Oe. grandiflora as indicated by these collections is overlapped by the much larger range of Oe. biennis. In all collections other than those of the Brewton population, the collectors had no reason to collect the far more common and weedy Oe. biennis, even though it may have occurred among the Oe. grandiflora plants. The Brewton collection, which attempted to sample the entire population, was made late in the season when the plants were already senescent. Although some individuals were suspected to belong to Oe. biennis, they could not be recognized with certainty. The collection was made at random among all of the oenotheras comprising the stand. Thus, the frequency of Oe. biennis in the sample should reflect its frequency in the natural population.

RESULTS-The Oenothera grandiflora phenotype-One of the most distinctive features of the grandiflora phenotype is the deeply scalloped leaf margin toward the base of the leaf. This is particularly striking in the rosette and lower cauline leaves. Nevertheless, among the different collections the degree of scalloping may vary, and occasional plants may show little, if any scalloping. Red flecks on the leaves (the maculans character) when the plants are young are also typical, although the degree of flecking is variable, and some plants may lack flecks entirely. Many of the plants show a wide range of variation in the amount of anthocyanin in the young leaves and stem. Some plants have clear green leaves with red to white midribs and green stems; others have leaves which, when young, have anthocyanin along the margins to give the plants a bronzed appearance, and stems which are a deep red. Such variation was found both within and between the Brewton cultures, as well as in the other collections. Although the red color may extend from the base of the stem nearly to the tip, the stem tip itself is characteristically green; the papillae at the base of the stem may be either green or red. The pubescence of the stem tip is not pronounced and consists primarily of erect and semi-erect hairs. In addition to the branches which develop from the base of the plant, there are those which arise from lateral buds very near the tip of the central shoot or a basal branch. Such clusters of small branches at the tips of the main shoots are characteristic of $O e$. grandiflora.

In general, Oe grandiflora strains, when field grown either in Duesseldorf or in Ann Arbor, Michigan, flower at the earliest in the beginning or middle of September by which time the low night temperatures have already reduced the growth and flower production. However, some collections, notably Monteagle, Bellamy, and Tuscaloosa, contained plants which bloomed as early as the latter part of July or the first of August. It is worth nothing that those grandiflora strains which have been maintained in our study collections in the North for many years bloom in July and August; selection has undoubtedly occurred, since the earliest bloomers are most likely to be selfed to maintain the strain. Plants exposed to short day 
treatment after breaking out of the rosette stage, flower by early July. In the case of the Brewton population sample, more than $50 \%$ of the treated plants were in bloom by the end of July, although the onset of flowering varied considerably, even within the same culture. A few plants did not form flower buds until late $\mathrm{Au}$ gust in spite of the short-day treatment. The untreated plants in the greenhouse began to flower in early August and were, with a few exceptions, in full flower by the end of the month. In the experimental garden, however, only a scattering of plants came into bloom during the latter half of August. The majority of the Brewton cultures did not reach full bloom until mid September. Nevertheless, at the end of September a number of plants throughout the cultures had not yet bloomed. The fact that the untreated Brewton plants in the greenhouse bloomed appreciably earlier than those in the field suggests that blooming time may depend upon night temperature as well as photoperiod. In any case, it is clear that the Brewton population shows considerable variability in blooming time, but that most grandiflora strains tend to flower in short days, although some collections may bloom in the longer days of mid or late summer.

Oenothera grandiflora typically produces yellowish green, tapered buds from 3 to $4 \mathrm{~cm}$ in length. The appressed sepal tips range from 3 to $7 \mathrm{~mm}$ long. Narrow, indistinct red stripes may occur where the sepals join one another. The buds are mostly glabrous with only a scattering of erect, glandular hairs. The petals range from 2.6 to $3.5 \mathrm{~cm}$ long and from 2.3 to 3.2 $\mathrm{cm}$ wide. The flowers are distinctly fragrant. When the flower is fully open, the base of the stigma is from 1 to $3 \mathrm{~mm}$ above the tip of the anthers; thus a pollinator is necessary for the transfer of pollen from anther to stigma. The seeds of Oe. grandiflora are black rather than brown in color and are longer and thinner than those of Oe. biennis.

The Oenothera biennis phenotype-The seven Oe. biennis cultures found among the Brewton population sample were not only uniform within each culture, but showed little, if any variability between cultures. Two appeared to be more highly mildew susceptible than the others. The leaves of the biennis forms are narrower and stiffer than those of the neighboring Oe. grandiflora plants. The rosette and lower cauline leaves tend to display incised margins at the base and exhibit red flecks. The margins of the cauline leaves turn upward, giving the leaf a boatlike appearance. The young stem tips are characterized by red papillae. At the very tip of the stem the region just below the bract is a bright red. The base of the stem is a dark red.

The Oe. biennis plants exposed to short day treatment bloomed by mid July; the plants in the garden, however, did not begin flowering until late September. Flowering within and between cultures was completely uniform. Because of the long period of vegetative growth, the plants reached a height of $2 \mathrm{~m}$.

Buds of the Brewton Oe. biennis range from 0.9 to $1.5 \mathrm{~cm}$ in length and are green with indistinct yellow bands. The sepal tips are flared, 2 to $3 \mathrm{~mm}$ in length. The buds are essentially glabrous. The petals are 1.0 to $1.5 \mathrm{~cm}$ wide and 1.1 to $1.7 \mathrm{~cm}$ long. In the fully open flower the anthers usually extend to the tips of the stigmatic lobes or beyond, insuring selfpollination.

It should be pointed out that Oe. biennis from the deep South differs from that of the Midwest in possessing incised leaf margins, red flecking, red stem tips, and dark red color of the lower stem. These characters are less likely to be found among the forms of the central and upper Midwest.

Cytological and compatibility behavior-The cytological and compatibility data for each collection are summarized in Tables 2 through 4 . Many, but not all, of the strains have been grown annually since first brought into cultivation. Except in the case of Brewton, the chromosomal configurations are based on a limited sample of one to several plants, although such sampling was often repeated in successive years. The occurrence of more than one configuration among the plants of a collection results from the presence of two or more chromosomal end arrangements. However, limitations of time and technical assistance have not permitted the determination of enough plants to detect all of the arrangements that may be present in each collection. Determination of many of these arrangements is still in progress, while in some cases strains exhibiting certain of the configurations have been lost.

The Bellamy collection, which presumably represents only a small sample of the natural population, nevertheless is made up of as many as four different chromosomal end arrangements. In the case of Brewton, all except seven of the 51 cultures each derived from a single plant in the Brewton population, were examined cytologically. Of these seven, four belonged to Oenothera biennis and in all likelihood possessed a $\odot 14$, the configuration exhibited by the remaining three Oe. biennis cultures which were examined. One hundred 
TABLE 2. Chromosomal end arrangements found among Oenothera grandiflora populations

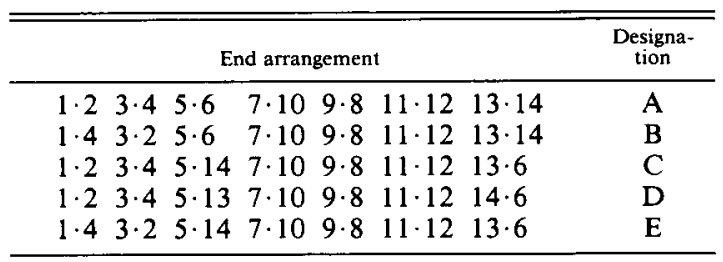

fourteen of the plants belonging to Oe. grandiflora were determined cytologically. Of these, 37 showed seven pairs of chromosomes at meiosis, 44 a circle of four and five pairs, and 32 two circles of four and three pairs. One plant exhibited a $\odot 10$ and two pairs. Seven plants in the progeny produced by selfing this plant were examined cytologically; six had seven pairs, while one had $\odot 10$, two pairs like the parent. In these cultures in which larger samples were determined (e.g., Culture \#5: nine plants; Culture \#34: 11 plants), all three of the commonly occurring configurations were found. In the 31 Oe. grandiflora cultures in which two or more plants were determined, only 15 showed a single configuration type.

It was possible to determine the segmental arrangements of 11 of the 14 plants from the Brewton cultures selected for such analysis. Eight plants had a configuration of seven pairs; two of these exhibited arrangement $A$, four arrangement $\mathrm{B}$, and two arrangement $\mathrm{C}$. Three plants possessed a configuration of $\odot 4$, five pairs; the analysis showed that one carried the arrangements $\mathrm{A}$ and $\mathrm{B}$, while the other two carried the arrangements $A$ and C. Presumably, a recombinant arrangement between $B$ and $C$, i.e., $1 \cdot 43 \cdot 25 \cdot 147 \cdot 109 \cdot 811 \cdot 1213 \cdot 6$ should
TABLE 4. Distribution of self-compatibility and incompatibility among Oenothera grandiflora populations

\begin{tabular}{lccc}
\hline \hline \multicolumn{1}{c}{ Race } & $\begin{array}{c}\text { Total no. of } \\
\text { plants tested }\end{array}$ & $\begin{array}{c}\text { No. } \\
\text { of Si } \\
\text { plants }\end{array}$ & $\begin{array}{c}\text { No. } \\
\text { of Sc } \\
\text { plants }\end{array}$ \\
\hline Avalon & 55 & 54 & 1 \\
Bellamy & 21 & 20 & 1 \\
Brewton & 113 & 0 & $113^{\mathrm{b}}$ \\
Martin Branch & unrecorded & 0 & all \\
Monteagle & 17 & 17 & 0 \\
Santa Rosa & 60 & 48 & 12 \\
Seabury Creek I & unrecorded & 0 & all \\
Seabury Creek II & unrecorded & 0 & all \\
Stockton I & unrecorded & 0 & all \\
Stockton II & unrecorded & 0 & all \\
York & 8 & 1 & 7 \\
\hline
\end{tabular}

a The unrecorded strains have been maintained in our collections for up to $20 \mathrm{yr}$ without any evidence of selfincompatibility in routine selfing and crossing. No tests for the presence of $\mathrm{ScSi}$ heterozygotes have ever been carried out, however.

b Two plants found which were ScSi heterozygotes; presumably such heterozygotes also occur in populations having both self-incompatible and self-compatible types.

also be present, but it was not found in the sample analyzed.

Compatibility behavior: One hundred thirteen plants were tested for self-compatibility. The one to several flowers which were hand pollinated on each of 56 plants all yielded normal fruits with one exception. In the latter case, three flowers were self-pollinated; the capsules appeared to develop normally but later turned brown prematurely and formed few seed. This was not interpreted as a case of self-incompatibility, however, because the behavior differs from that of self-incompatible forms in which capsules may persist for a time after pollination but fail to enlarge and ultimately

TABLE 3. Cytological characteristics of various populations of Oenothera grandiflora

\begin{tabular}{|c|c|c|c|}
\hline Population & First grown & Chromosomal configurations & $\begin{array}{l}\text { Chromosomal end } \\
\text { arrangements so } \\
\text { far determined }\end{array}$ \\
\hline Avalon & 1979 & $\odot 4,5$ prs; 7 prs & A, B \\
\hline Bellamy & 1976 & $\odot 6,4$ prs; $\odot 4, \odot 4,3$ prs; $\odot 4,5$ prs & $\mathrm{A}, \mathrm{C}, \mathrm{D}, \mathrm{E}$ \\
\hline Brewton & 1982 & $\odot 10,2$ prs; $\odot 4, \odot 4,3$ prs; $\odot 4,5$ prs; 7 prs & $\mathrm{A}, \mathrm{B}, \mathrm{C}$ \\
\hline Martin Branch & 1968 & 7 prs & A \\
\hline Monteagle & 1980 & $\odot 6, \odot 4,2$ prs; $\odot 4, \odot 4,3$ prs & C \\
\hline Santa Rosa & 1979 & $\odot 6,4$ prs; $\odot 4, \odot 4,3$ prs; $\odot 4,5$ prs; 7 prs & A, C \\
\hline Seabury Creek I & 1963 & 7 prs & $\mathbf{A}^{\mathbf{b}}$ \\
\hline Seabury Creek II & 1963 & $\odot 4,5$ prs; 7 prs & $\mathrm{A}, \mathrm{C}$ \\
\hline Stockton I & 1963 & 7 prs & $\mathbf{A}^{\mathbf{b}}$ \\
\hline Stockton II & 1963 & 7 prs & undetermined \\
\hline Tuscaloosa & 1967 & 7 prs & A \\
\hline York & 1971 & $\odot 4,5$ prs; 7 prs & A, C \\
\hline
\end{tabular}

a See Table II for the arrangements indicated by the letter designations.

b Determined by Cleland (1972). 
drop off. Another 57 plants were tested for selfcompatibility by pollinating excised flowers and determining if pollen tubes developed. No evidence of self-incompatibility was found.

The results from the crosses designed to test the sample of 21 Brewton plants for the presence of sequestered $\mathrm{Si}$ alleles revealed that two of the plants were $\mathrm{ScSi}$ heterozygotes.

DisCUSSION-In contrast to the earlier view of the species, Oenothera grandiflora consists of populations which are cytogenetically diverse both with regard to chromosomal end arrangement and compatibility behavior. Within the limits that characterize the species, morphological variation also occurs, as might be expected in what are basically structurally homozygous, outbreeding forms. The meiotic configurations found among the various collections indicate that different chromosomal end arrangements must be present within single populations. The end arrangements so far identified are listed in Table 2. Arrangement $A$ is found in ten of the collections, $B$ in three, $C$ in four, $D$ in one, and $E$ in one of the collections. Since D and E appear to be rare, recombinants involving them are not likely be observed in our small sample, if they do exist. Nevertheless, the $\odot 6, \odot 4$, two pairs found in the Monteagle collection and $\odot 6$, four pairs in the Bellamy and Santa Rosa strains as well as the $\odot 10$, two pairs from the Brewton population indicate that additional arrangements will be found if larger population samples can be analyzed.

Of the 22 complexes found in the 11 plants of the Brewton collection whose arrangements have been determined, seven have the $A$, nine the $B$, and six the $C$ arrangement. These frequencies are not significantly different from equality $\left(\chi^{2}=0.769\right)$. Thus, if we assume that the three arrangements occur with equal probability and the population is random breeding, then the expected frequencies of meiotic configurations should be 0.333 plants with seven pairs, 0.444 with a $\odot 4$, five pairs and 0.222 with $\odot 4, \odot 4$, three pairs. The actual frequencies observed are respectively, $0.33,0.39$, and 0.28 . The deviation is clearly not significant $\left(\chi^{2}=2.68\right)$. The latter data suggest that the $\mathrm{A}$, $B$, and $C$ chromosomal end arrangements do not differ in selective value. On the other hand, the failure to detect the recombinant arrangement may be evidence that only certain arrangements have general adaptive value and become widely distributed.

The significance of the meiotic configuration of $\odot 10$, two pairs found in the one plant of the Brewton sample remains unclear. The plant unquestionably possessed the grandiflora phenotype; it could not be interpreted as a simple hybrid between Oe. biennis and Oe. grandiflora. Only a hybrid combining an alpha biennis 1 with a grandiflora complex could conceivably approach the grandiflora phenotype. However, it would likely have smaller flowers than the grandiflora parent. Further, the configuration of $\odot 10$, two pairs seems highly unlikely for such a complex combination. On the other hand, certain of the seven paired segregates from the progeny of the selfed $\odot 10$, two pairs plant exhibit characters that are generally associated with the phenotype of the A type complexes (villosa, or formerly known as the strigosa type complex). These plants are under further study. Crosses have also been made to determine the segmental arrangements present in the original $\odot 10$, two pairs plant.

If plants with large circles at meiosis do occur among Oe. grandiflora populations, one can conclude that complex heterzygotes can arise within structurally homozygous populations through random segmental interchange unaccompanied by significant genetic differentiation of the various segmental arrangements which may occur. This is in contrast to the commonly held view that complex heterozygotes are the result of the segmental differentiation of isolated populations which later came together and hybridized. Cytogenetic analysis of the plant exhibiting the $\odot 10$, two pairs should throw light on the matter; if the complexes have actually been derived from those of Oe. grandiflora, both segmental arrangements should show the relationship.

Of considerable interest is the fact that the Brewton population sample did not contain any hybrids between $O e$. biennis and Oe. grandiflora in spite of the two species growing side by side. The grandifloras are clearly cross-pollinated and the transfer of pollen between plants of the two species is to be expected. However, plants suspected to be hybrids have been found in certain of the populations observed during the 1983 field studies.

Oenothera grandiflora was long believed to be a self-compatible species. In 1979 Stubbe and Raven reported finding self-incompatible plants among those grown from seed collections from York and Bellamy, Alabama (Stubbe and Raven, 1979). Further work reported here has revealed self-incompatible plants in collections from Avalon, Florida, Santa Rosa County, Florida, and Monteagle, Tennessee; in addition, Si alleles occurring in the heterozygous condition have been found in the Brewton and Seabury Creek, Alabama populations (see Table 2). The latter site is not far from the 
locality where Bartram originally discovered Oe. grandiflora. The pattern of distribution of self-compatibility and incompatibility in the grandiflora populations and its significance remains an open question until larger samples of more populations can be analyzed. The Brewton collection was an initial effort in this direction; the 113 plants in the Brewton cultures which were tested proved to be self-compatible. However, the crosses made to detect hidden Si alleles revealed that two plants out of the 21 analyzed were ScSi heterozygotes.

If we accept the dogma that self-compatibility is the derived condition, then Oenothera grandiflora appears to be in an evolutionary transition from the self-incompatible to the self-compatible state. Only the Monteagle population seemed to be composed entirely of selfincompatible forms, although the sample tested may have been too small to be representative. The Avalon and Santa Rosa populations appear to be predominantly self-incompatible. Otherwise, the collections behaved as predominantly or entirely self-compatible. These results imply that self-compatibility has a selective advantage over self-incompatibility.

Those collections which are self-compatible do not seem to differ in such characters as fragrance, large flower size, and the differential length of stamens and stigma, all of which favor cross-pollination. The Brewton population has not diminished in variability through being self-compatible and in this sense suffers no disadvantage when compared with self-incompatible populations. On the other hand, selfcompatible plants may be favored depending upon the behavior of pollinators. Pollinators often move from flower to flower on the same plant; these pollinations will be successful on a self-compatible plant, but not on a self-incompatible one. If pollinator activity for one reason or another is limited, the self-compatible members of the population are likely to produce more seed. Self-pollination may also occur in Oe. grandiflora when an unpollinated stigma reaches maturity and begins to wilt, bringing it into contact with the anthers of the flower. Self-compatible plants may thus increase their relative contribution to the seed pool. Moreover, in populations in which the number of $\mathrm{Si}$ alleles is restricted, a degree of cross-incompatibility is likely to occur as a result of pollinations between plants carrying identical $\mathrm{Si}$ alleles. With limited pollination, self-compatible plants should have an advantage in seed production. A further advantage of self-compatibility is that colonization of a new site can be achieved by a single individual. In light of the above considerations it seems reasonable to expect a continuing evolution toward self-compatibility in this species.

The results of the current study provide further evidence for the long held view that the alpha complexes of Oe. biennis were derived from Oe. grandiflora. The chromosomal end arrangement most commonly found among these alpha complexes (Arrangement C) is now shown to occur regularly in grandiflora populations. Moreover, alpha biennis complexes possess $\mathrm{Si}$ alleles; before $\mathrm{Si}$ alleles were found in Oe. grandiflora, it was difficult to understand why they were not present, if the grandiflora complexes were ancestral to the alpha biennis complexes. This puzzle has now been solved.

The original geographic range of Oe. grandiflora as well as its current "natural" range remains uncertain; the literature on the subject is limited and contradictory. In the account of his travels throughout the Southeast, first published in 1791, William Bartram relates first encountering Oe. grandiflora growing in uncultivated fields a few miles above Taensa ${ }^{2}$ (Alabama) as he was proceeding up the eastern channel of the Mobile River. This was a few days after leaving Mobile on August 5th; he states that "there is a profusion of bloom for many weeks."

According to Harper, ${ }^{3}$ the species name, grandiflora, may have originally been proposed by Bartram when he sent specimens to Fothergill. In any case, the name was applied when the species was described in Aiton's Hortus Kewensis in 1789.

Gates (1910) reporting on a study of early records of oenotheras, claims that Oenothera grandiflora originally grew in Virginia and the Carolinas and may have been introduced into Europe from there in the early 1600s; Gates argues that it was from this early introduction that the Oe. grandiflora growing wild in England was derived and that it represents an eastern form of the species, showing certain differences from its Alabama relative. The evidence for Gates' conclusion is not convincing, however.

Barton (1821) states that Oe. grandiflora is "found native in the woods and fields and about habitations in Carolina and Georgia," but in the same description calls attention to the opinion of Elliott (1821) that Oe. grandiflora is "grown in gardens and around buildings; certainly not indigenous in the low country." Darby (1860) says that Oe. grandiflora is found on

\footnotetext{
2 Spelling at Bartram's time; now "Tensaw."

${ }^{3}$ In an article in the Mobile Press-Register, September $16,1962$.
} 
cultivated grounds. Chapman (1865) fails to even mention Oe. grandiflora in his Flora of the Southern United States. According to Small (1933), Oe. grandiflora occurs in woods, on river banks and roadsides on the coastal plain of Alabama. Rickett (1967), on the other hand, believes that Oe. grandiflora is "found but rather rarely in Alabama, Mississippi, and Tennessee." Duncan and Foote (1975) note Oe. grandiflora as "rare, occurring in woods and waste places of the Alabama Coastal Plain"; they consider it to be an escape from cultivation elsewhere.

Vail (1905) in a brief note relating to $O e$. grandiflora, remarks that "evidence is fairly conclusive that the Oe. grandiflora Ait. so well and so long established in cultivation (present authors' italics) originated from seed sent to Fothergill by William Bartram after his famous travels through the southern United States." Harper (1947) includes Oe. grandiflora in a listing of flowering plant species endemic to Alabama. He states, "these are plants which have never been found in any other state." Harper must certainly have been aware of reports of Oe. grandiflora from other states, but undoubtedly considered these to be introductions from the Bartram locality through cultivation.

Dr. Peter Raven has kindly furnished locality information from labels of herbarium specimens determined to be Oe. grandiflora which were assembled in connection with his taxonomic studies of the genus (Raven, Dietrich and Stubbe, 1979). Of the 53 specimens for which information was provided, 14 were collected in Florida, 12 in Alabama, nine in Mississippi, six in Tennessee, six in North Carolina, and three in South Carolina. Three came from northern sites where they must almost certainly have been introduced. The Alabama, Mississippi and most of the Florida collection sites can be interpreted to represent the general area where Bartram originally discovered $O e$. grandiflora; three of the Florida specimens were collected in central Florida, however. The Tennessee collection sites seem to be largely clustered in two counties in the south central part of the state near the Alabama border. In North and South Carolina the sites seem to be scattered.

One cannot exclude the possibility that the species has been distributed from the Mobile area through cultivation rather than having a wider range in earlier times. Several authors have noted that the species is rare; our own experience in 1981 appeared to confirm this view. However, the search for additional populations in the 1983 season, undertaken in late
August-early September in southern Alabama, located seven new sites. Interestingly, at none of these did the capsules contain ripe seed. As a result, the area was revisited in mid-October in order that seed could be collected. Six new populations were discovered, some of which were on routes previously traveled. The obvious explanation for having missed the latter earlier is that they were not in bloom at the time. The large, pale yellow flowers of Oe. grandiflora are distinctive enough that they are easily spotted even when driving at the speed limit. On the other hand, plants that are not flowering are difficult to distinguish in the general vegetational background. Many of the populations still bloom abundantly in mid-October. Moreover, in several stands the oldest capsules were no more than 3 to $4 \mathrm{wk}$ old and the seed not fully mature. The blooming period of Oe. grandiflora thus appears to extend from early August until late October in its native habitat.

Since Oenothera biennis is often found intermingled with Oe. grandiflora and grows throughout the latter's range, one must ask how Oe. grandiflora is able to retain its integrity. A possible explanation is that the species is at least partially isolated because many of its strains bloom late in the season after Oe. biennis has finished flowering.

Populations as well as single plants frequently occur in widely scattered locations; one is led to believe that dispersal occurs by birds which eat the seeds. Direct evidence for this is lacking, although sparrows are regularly observed to eat the seeds out of the capsules. Presumably some seeds are still viable at the time they are voided.

A sufficient number of grandiflora sites have now been observed to venture some generalizations about the ecology of the species. Oenothera grandiflora, like its relative, Oe. bien$n i s$, is found in waste places and disturbed habitats, but why it is far less common remains a puzzle. The Brewton population occurred on a sandy river flat which undoubtedly is periodically flooded. The plants, 5 to $6 \mathrm{ft}$ tall, grew above a dense tangle of vegetation forming a layer 1 to $2 \mathrm{ft}$ high above the soil in most places. Plants growing in a similar river flat situation were also found at another location. Several stands were seen in old fields or along roadsides where disturbance is frequent. In many instances, the soil is nearly pure sand. Kral (pers. commun.), who collected the Monteagle strain, found the plants forming a large population in a typical roadside habitat, yet 2 years later had difficulty finding enough plants to make a seed collection. 
Some plants were found growing close to the edge of woods where it would seem that the shade would put them at a competitive disadvantage. One roadside site was particularly striking in that the Oe. grandiflora plants were literally embedded in a dense mass of tall herbs, shrubs, and vines, but projecting high enough above the growth to expose numerous branches bearing flowers. These plants were between 8 and $12 \mathrm{ft}$ tall. The seedlings must have had to grow rapidly early in the season in order to compete with the surrounding vegetation.

In cultivation Oe grandiflora does not behave significantly different from the many strains of Oe. biennis that have been grown in the experimental garden.

It is clear that Oe. grandiflora warrants further study on several counts. Analysis of the newly collected population samples should elucidate some of the questions the current study has raised.

\section{LITERATURE CITED}

Aiton, W. 1789. Hortus Kewensis. Vol. II. London. Barton, W. P. C. 1821. A flora of North America. M. Carey and Sons, Philadelphia.

BARTRAM, W. 1791. Travels through North and South Carolina, Georgia, East and West Florida, the Cherokee Country, the extensive territories of the Mus- cogulges or Creek Confederacy, and the Country of the Choctaws. James and Johnson, Philadelphia.

- 1958. Travels (edition with commentary and annotated index by Francis Harper). Yale University Press, New Haven.

Chapman, A. W. 1865. Flora of the Southern United States. Ivison, Phinney and Co., New York.

Cleland, R. E. 1972. Cytogenetics and evolution of Oenothera. Academic Press, New York.

DARBY, JoHN. 1860. Botany of the southern states. A S. Barnes and H. L. Burr, New York.

Duncan, W. H., AND L. E. FoOTE. 1975. Wildflowers of the southeastern United States. University of Georgia Press, Athens.

Elliotr, S. 1821. A sketch of the botany of South Carolina and Georgia. J. R. Schenck, Charleston.

GATES, R. R. 1910. Early historico-botanical records of the Oenotheras. Proc. Iowa Acad. Sci. 17: 85-124.

HAR PER, R. M. 1947. Preliminary list of endemic flowering plants of Alabama. J. Ala. Acad. Sci. 18: 70.

Raven, P. H., W. Dietrich, and W. Stubbe. 1979. An outline of the systematics of Oenothera subsect. Euoenothera (Onagraceae). Syst. Bot. 4: 242-252.

RicketT, H. W. 1967. Wild flowers of the United States. McGraw-Hill, New York.

Small, J. K. 1933. Manual of the southeastern flora. (Publ. by Author.) New York.

Stubbe, W., And P. H. Raven. 1979. Genetic self-incompatibility in Oenothera subsect Euoenothera. Science 204: 327.

VAlL, A. M. 1905. Onagra grandiflora (Ait.), a species to be included in the North American flora. Torreya 5: 9-10. 